\title{
Cardiac surgery: moving away from intensive care
}

\author{
Jin Long Chong, Ravi Pillai, Anthony Fisher, Catherine Grebenik, Michael Sinclair, \\ Stephen Westaby
}

Department of Cardiac Surgery, Oxford Heart Centre, John Radcliffe Hospital, Oxford $\mathrm{J}$ L Chong $\mathrm{R}$ Pillai

A Fisher

C Grebenik

$M$ Sinclair

$S$ Westaby

Correspondence to: Mr Ravi Pillai, Departmen of Cardiac Surgery, John Radcliffe Hospital, Headle Way, Oxford OX3 9DU.

Accepted for publication 8 April 1992.

\begin{abstract}
Objective-To evaluate outcome in patients managed outside an intensive care unit after open heart surgery.

Background-The high cost of cardiac surgery is mainly due to the needs of traditional postoperative care. The requirements for intensive care and treatment has decreased with improvements in techniques of cardiac surgery and anaesthesia. In this setting the need to continue to depend on intensive care units for the recovery of cardiac surgical patients is questionable on clinical and economic grounds.

Design-Postoperative outcome in 245 patients over a four month period was studied prospectively.

Patients-Mean age of the patients was $63 \cdot 2$ years. They underwent a wide variety of operative procedures. Ninety percent of them recovered in a dedicated three bed cardiac surgical recovery area where the management protocol led to rapid extubation and step down in dependency care.

Results-Median time for ventilatory support was 90 minutes after transfer to the area. Only five patients were subsequently admitted to the general intensive care unit for prolonged respiratory and cardiac support. Ten patients were electively admitted to the general intensive care unit. Two deaths occurred in hospital in this group $(0 \cdot 8 \%)$. Four patients were ventilated for 24 hours in the recovery area itself and made an uncomplicated recovery.

Conclusion-This study confirms that over $90 \%$ of patients undergoing cardiac surgery would recover safely and be treated effectively in a more economical area than intensive care.
\end{abstract}

(Br Heart J 1992;68:430-3)
The past decade has seen a substantial increase in the demand for cardiac surgery principally through the acknowledged benefits of myocardial revascularisation. Cardiac surgery proves cost effective in terms of quality adjusted life years by improving capacity for work, longevity, and quality of life in all age groups ${ }^{1}$ This is, however, an expensive speciality and if we can reduce the cost of heart operations, the procedures may achieve still higher priority. The single factor that differentiates open heart surgery from other forms of surgery is cardiopulmonary bypass (CPB). Cardiac surgical patients traditionally occupy high dependency beds in an intensive care unit for up to 36 hours because of the damaging effects of cardiopulmonary bypass and prolonged anaesthesia. ${ }^{23}$ In Oxford an intensive care bed costs over $£ 750$ and a recovery bed around $£ 380$ a day. Does modern cardiac surgery justify this expense or can costs be reduced without compromising safety by a fresh approach to the practical and organisational aspects of the speciality?

Improvements in extracorporeal technology with membrane oxygenation, arterial line filtration, and blood sparing techniques have reduced the cerebral, pulmonary, renal, and bleeding complications of cardiopulmonary bypass. Most cardiac operations are immediately beneficial when patients have surgery at an early stage of their disease. ${ }^{4}$ Changes in anaesthetic and perfusion techniques now routinely allow extubation within two hours of surgery in a cardiac recovery area within the operating theatre complex. This produces a rapid step down in dependency level and therefore lower costs. The results of postoperative care for 245 consecutive adult patients undergoing both elective and emergency open heart surgery at the Oxford Heart Centre have been analysed.

Patients and methods

Between 1 January and 30 April 1990, 197 men

Table 1 Cardiac surgery in Oxford Heart Centre January to April 1990 ( a four month period, $n=245$ )

\begin{tabular}{|c|c|c|c|c|c|c|}
\hline Type of operation & $C A B G$ & $M V R$ & $A V R$ & $\begin{array}{l}A V R \text { and } \\
M V R\end{array}$ & $\begin{array}{l}C A B G \text { and } \\
\text { valve }(s)\end{array}$ & Miscellaneous \\
\hline $\begin{array}{l}\text { No } \\
\text { Age (mean (range)) (y) } \\
\text { Hospital stay (mean (SD)) (days) }\end{array}$ & $\begin{array}{cl}167 & \\
60 & (38-76) \\
7 \cdot 3 & (2 \cdot 2)\end{array}$ & $\begin{array}{l}17 \\
62 \cdot 3(35-76) \\
8 \cdot 5(2 \cdot 0)\end{array}$ & $\begin{array}{ll}28 \\
62 \\
8 \cdot 2 & (37-75) \\
(2 \cdot 4)\end{array}$ & $\begin{aligned} 4 & \\
56 \cdot 5 & (49-62) \\
7 \cdot 8 & (1 \cdot 7)\end{aligned}$ & $\begin{array}{l}19 \\
69 \cdot 3(63-75) \\
8 \cdot 3(2 \cdot 0)\end{array}$ & $\begin{array}{cc}10 \\
37 \cdot 6 \\
6 & (20-64) \\
(1 \cdot 0)\end{array}$ \\
\hline
\end{tabular}

Hospital deaths, two (0.8\%); CABG, coronary artery bypass grafts; MVR, mitral valve replacement; AVR, aortic valve replacement. 
and 48 women underwent cardiac surgery with cardiopulmonary bypass. The mean age for all the patients was 63.2 (range 20 to 77 ) years (table 1$)$. Ninety seven $(39.5 \%)$ patients were older than 65 . Two separate areas were designated for adult postoperative care. Firstly, and preferentially, a three bed cardiac surgical recovery area within the operating theatre complex, and secondly the general intensive care unit, which had previously been used routinely to admit all patients after open heart surgery.

The cardiac surgical recovery area has facilities for intermittent positive pressure ventilation, continuous monitoring of the electrocardiogram, arterial and central venous pressure, and provisions for basic cardiovascular support. This unit operates continuously from Monday to Saturday morning, but unlike the general intensive care unit, it is not routinely staffed at the weekend.

Transfer of patients to the general intensive care unit was based on specific criteria. These included preoperative multisystem organ failure, very poor left ventricular function requiring prolonged intra-aortic balloon pump support, poor respiratory function with special ventilatory requirements, and patients who sustained an unexpected event preoperatively. It was estimated that this would amount to $5 \%-7 \%$ of the adult practice. All other patients including those after cardiac reoperation, acute aortic dissection, double valve replacement, or patients with preoperative renal failure requiring haemodialysis were managed in the cardiac surgical area.

Patients operated on and extubated in the morning were transferred to the cardiac surgical floor in the afternoon allowing one recovery bed to be used twice. Because five to six adult open heart operations were performed each day, restriction of the cardiac surgical recovery area to three beds meant that, for logistical reasons a small proportion of patients who would normally be admitted to this area were cared for in available general intensive care beds.

\section{SURGICAL TECHNIQUES}

All surgical procedures were performed with cardiopulmonary bypass using a Cobe CML membrane oxygenator and Pall $40 \mu \mathrm{m}$ arterial line filter. Table 1 summarises the operations performed. Coronary artery bypass surgery was undertaken with either cold potassium cardioplegia and moderate hypothermia (30 $\left.-32^{\circ} \mathrm{C}\right)(\mathrm{n}=89)$ or intermittent aortic cross clamping and fibrillation $(n=78)$. All valve replacements were performed with cold potassium cardioplegia and moderate systemic hypothermia, as were combined valve plus coronary bypass procedures and other operations. Patients were rewarmed to $37^{\circ} \mathrm{C}$ before weaning from cardiopulmonary bypass.

\section{ANAESTHETIC TECHNIQUES}

All drugs apart from aspirin were continued until the morning of operation. Patients were premedicated with $10-20 \mathrm{mg}$ papaveretum and $0.04 \mathrm{mg}$ hyoscine intramuscularly. Before the induction of anaesthesia radial arterial and peripheral venous access was made under local anaesthesia. With an electrocardiogram and monitoring arterial pressure anaesthesia was induced and maintained with fentanyl (10-15 $\mu \mathrm{g} / \mathrm{kg}$ ) and thiopentone (1-3 $\mathrm{mg} / \mathrm{kg}$ ) or etomidate $(0 \cdot 1-0.3 \mathrm{mg} / \mathrm{kg})$, and pancuronium bromide $(0.15 \mathrm{mg} / \mathrm{kg})$. After endotracheal intubation a triple lumen central venous cannula was inserted into the right internal jugular vein. Anaesthesia was maintained with nitrous oxide and halothane. Glycerlyl trinitrate infusion was used to control hypertension.

During cardiopulmonary bypass the patient received a continuous infusion of propofol (4-6 $\mathrm{mg} / \mathrm{kg} / \mathrm{h})$ and atracurium $(0.5 \mathrm{mg} / \mathrm{kg})$. At the end of the procedure patients were given $0.5 \mathrm{mg}$ glycopyrrolate with $2.5 \mathrm{mg}$ neostigmine to reverse the residual muscle paralysis, and were transferred to the cardiac recovery area or intensive care unit.

\section{POSTOPERATIVE MANAGEMENT}

After admission to the cardiac surgical recovery area all patients were weaned from ventilatory support as soon as they established haemodynamic stability and stopped bleeding. When the patients regained consciousness intermittent positive pressure ventilation was discontinued and they were connected to a Mapleson C circuit with an oxygen flow of $6 \mathrm{l} / \mathrm{min}$ and allowed to breathe spontaneously. ${ }^{5}$ The patient remained intubated until satisfactory gas exchange was achieved as confirmed by serial arterial blood gas analysis. These are judged as being within acceptable parameters if on an inspired oxygen fraction of $<0.5$ the $\mathrm{PaO}_{2}$ is $>10 \mathrm{kPa}$ and $\mathrm{PaCO}_{2}$ is $\leqslant 7.5 \mathrm{kPa}$. Unless extubated in the operating theatre itself, the decision to wean and extubate patients was initiated by the specially trained nursing staff of the cardiac surgical recovery area. Throughout the weaning process and after extubation arterial blood gas analysis and pulse oximetry were closely monitored. Postoperative analgesia was achieved with a morphine infusion at 1-3 $\mathrm{mg} / \mathrm{h}$. An early postoperative chest $x$ ray film was only obtained if clinically indicated. Usually the first chest $x$ ray film was taken after removal of the chest drains.

The time of discharge from the cardiac surgical recovery area depended on the number of operations planned each day. The fittest patients were operated on early in the day to facilitate uncomplicated recovery and transfer to the floor within four to six hours of operation, allowing reuse of the recovery space.

\section{Results}

We studied 245 consecutive patients of which $48(19 \cdot 6 \%)$ were women.

ADMISSION TO CARDIAC SURGICAL RECOVERY AREA Two hundred and twenty $(90 \%)$ patients were electively admitted to the cardiac surgical recovery area, $70 \%$ after coronary artery bypass surgery, the rest mostly after simple or combined valve operations. The miscellaneous group of 10 patients included two patients who had composite aortic root replacement with 
Table 2 Site of postoperative recovery

\begin{tabular}{lcl}
\hline & $\begin{array}{c}\text { Admissions to } \\
\text { recovery area }\end{array}$ & $\begin{array}{c}\text { Admission to general } \\
\text { internal care unit }\end{array}$ \\
\hline CABG & $153(91.6 \%)$ & 14 \\
AVR & $27(96.4 \%)$ & 1 \\
MVR & $14(82 \cdot 3 \%)$ & 3 \\
AVR and MVR & $4(100 \%)$ & 0 \\
CABG and valve(s) & $13(68.4 \%)$ & 6 \\
Miscellaneous & $9(90 \%)$ & 1 \\
Total & 220 & 25 \\
\hline
\end{tabular}

Footnotes as for table 1.

reimplantation of the coronary arteries. Of the 167 patients undergoing coronary artery bypass surgery (mean (SD) grafts/patient were $2 \cdot 8(0 \cdot 6)$ ) at least one internal mammary artery was used in $55 \%$ of cases. Ninety eight patients $(58.7 \%)$ had three grafts or more. Fifty eight patients $(85.3 \%$ of all valves) were admitted to the cardiac surgical recovery area after valve replacement; of these $17(29 \%)$ had combined coronary artery bypass graft and valve surgery or underwent double valve replacement (table 2)

Total time (mean (SD)) on cardiopulmonary bypass ranged from 45 (13.9) minutes for mitral valve replacement to $79(22 \cdot 2)$ minutes for double valve replacement (table 3 ). Patients undergoing coronary artery bypass surgery $(68 \cdot 2 \%)$ were on cardiopulmonary bypass for $57(15 \cdot 7)$ minutes with a mean aortic cross clamp time of $32(11.9)$ minutes.

\section{EXTUBATION TIME}

The median time on ventilatory support after admission to the cardiac surgical recovery area was 90 minutes (range 0-18 hours) with removal of the endotracheal tube (table 4) at a median time of 120 minutes (range $0-18$ hours). The mean $\mathrm{PaO}_{2}$ and $\mathrm{PaCO}_{2}$ (table 5) were 14.38 $(4.26) \mathrm{kPa}$ and $6.23(0.63) \mathrm{kPa}$ at two hours and $16.68(4.0) \mathrm{kPa}$ and $6.02(0.64) \mathrm{kPa}$ at four hours after extubation respectively. The inspired oxygen fraction was $0.25-0.3$ on a variable flow oxygen mask with a four litre oxygen flow. Four patients $(1.8 \%)$ required reintubation after early extubation (one for respiratory apnoea) and three patients were returned to the operating theatre for excessive bleeding. Four patients $(1.8 \%)$ were assessed to be unfit for safe return to the general floor on the next day and continued to be managed in the cardiac surgical recovery area for more than 24 hours.

\section{MORTALITY}

There were two deaths $(0 \cdot 8 \%)$. One 46 year old

Table 3 Mean (SD) duration of operation, cardiopulmonary bypass, and aortic cross clamp times ( $\mathrm{min}$ )

\begin{tabular}{lllll}
\hline & $\begin{array}{l}\text { Duration of } \\
\text { operation }\end{array}$ & \multicolumn{2}{l}{$\begin{array}{l}\text { Duration of } \\
\text { bypass }\end{array}$} & $\begin{array}{l}\text { Duration of } \\
\text { cross clamp }\end{array}$ \\
\hline CABG & $152(36)$ & $57(15)$ & $32(12)$ \\
AVR & $144(35)$ & $57(18)$ & $45(12)$ \\
MVR & $133(19)$ & $45(14)$ & $31(1)$ \\
AVR and MVR & $171(23)$ & 79 & $(19)$ & $64(18)$ \\
CABG and valves & $187(34)$ & $75(17)$ & $56(14)$ \\
Miscellaneous & $113(28)$ & $20(5 \cdot 5)$ & $11(3)$ \\
\hline
\end{tabular}

Footnotes as for table 1.
Table 4 Median duration of ventilatory support in cardiac surgical recovery area

\begin{tabular}{lcc}
\hline & $\begin{array}{l}\text { Duration of } \\
\text { ventilatory } \\
\text { support }\end{array}$ & $\begin{array}{l}\text { Extubation } \\
\text { time (min) }\end{array}$ \\
\hline CABG & 60 & 120 \\
AVR & 120 & 150 \\
MVR & 90 & 135 \\
AVR and MVR & 210 & 240 \\
CABG and valves & 65 & 125 \\
Miscellaneous & 10 & 30 \\
\hline
\end{tabular}

Footnotes as for table 1 .

woman with triple vessel disease and recent myocardial infarction died after coronary artery surgery. She had had bilateral varicose veins stripped, and she received two saphenous vein homografts one of which was acutely rejected and thrombosed soon after operation. She died from an extension of her myocardial infarction 11 hours after operation. The second patient was a 64 year old man with severe mitral valve disease who died following acute dissection of the ascending aorta three days after the initial operation.

\section{ADMISSION TO THE INTENSIVE CARE UNIT}

Twenty five patients were admitted to the intensive care unit. Of these, $10(40 \%)$ patients were admitted due to lack of space in the recovery area. Five patients $(2 \cdot 25 \%)$, having been initially admitted to the cardiac surgical recovery area, were transferred to the intensive care unit for prolonged inotropic and respiratory support on the operative day (table 6). Ten patients were electively admitted to this area on the basis of their preoperative assessment.

\section{HOSPITAL STAY}

The mean duration of postoperative hospital stay (table 1) was 7.5 (95\% range 5-12) days. Sixty eight per cent of coronary artery bypass patients were discharged on the sixth postoperative day. The Oxford Heart Centre allocates 3.7 nursing staff for each recovery bed as opposed to $7 \cdot 2$ for a bed in the general intensive care unit. The cardiac recovery area is staffed only during weekdays, unlike the general intensive care unit, which is staffed at a constant level for seven days a week irrespective of patient workload. Particularly cost effective in the cardiac surgical recovery area is the rapid turnover with a single recovery bed used for more than one patient in 24 hours.

\section{PRESENTATION OF DATA}

All data are presented as means (SD) where the results are normally distributed and as medians were the distribution is not normal.

\section{Discussion}

Advances in anaesthetic, surgical, and perfusion techniques have resulted in an improved outcome after cardiac surgery. Attitudes towards postoperative care, however, have not kept pace with these improvements. Our hypothesis was that attenuation of the damaging effects of cardiopulmonary bypass, in 
Table 5 Arterial blood gases (mean (SD) partial pressure) after extubation in the postoperative period

\begin{tabular}{|c|c|c|c|c|c|c|}
\hline \multirow[b]{2}{*}{$\begin{array}{l}\mathrm{PaO}_{2}(\mathrm{kPa}) \\
\mathrm{PaCO}_{2}(\mathrm{kPa}) \\
\mathrm{pH} \\
\text { Base excess }\end{array}$} & \multicolumn{2}{|c|}{ Before extubation } & \multicolumn{2}{|c|}{$2 \mathrm{~h}$ after extubation } & \multicolumn{2}{|c|}{$4 \mathrm{~h}$ after extubation } \\
\hline & $\begin{array}{r}21.86 \\
4.93 \\
7.38 \\
-2.7\end{array}$ & $\begin{array}{l}(7 \cdot 7) \\
(0 \cdot 9) \\
(0 \cdot 06) \\
(1 \cdot 7)\end{array}$ & $\begin{array}{c}14 \cdot 38 \\
6 \cdot 23 \\
7 \cdot 29 \\
-3.9\end{array}$ & $\begin{array}{l}(4 \cdot 26) \\
(0.63) \\
(0.04) \\
(2.5)\end{array}$ & $\begin{array}{r}16 \cdot 68 \\
6 \cdot 02 \\
7 \cdot 31 \\
-2 \cdot 6\end{array}$ & $\begin{array}{l}(4 \cdot 0) \\
(0 \cdot 64) \\
(0 \cdot 03) \\
(2 \cdot 13)\end{array}$ \\
\hline
\end{tabular}

association with a shorter operative and anaesthetic time, would allow safe and early extubation with a rapid step down in medical and nursing dependency care. In this prospective study of common adult cardiac surgical procedures we have shown that postoperative recovery can be safely managed outside a conventional intensive care unit in $90 \%$ of patients.

Age is not an adverse factor in selecting patients for this type of postoperative care. Almost $40 \%$ of the patients recovered in this facility were over 65 years old. The range of the surgical procedures confirmed the preponderance of surgery for ischaemic heart disease, and showed that patients with long standing valvar disease may be safely managed in this way. In fact, $85.8 \%$ of patients undergoing isolated or combined valve procedures were managed in the cardiac surgical recovery area.

Contemporary techniques of open heart surgery have led to an appreciable reduction in aortic cross clamp, cardiopulmonary bypass, and total operating time. In this series $84.5 \%$ of the operations were completed within $90 \mathrm{~min}$ utes from incision to closure (table 3). Expeditious surgery prevents early complications that are associated with inadequate myocardial preservation or excessive bleeding. Bleeding is particularly related to extended cardiopulmonary bypass. It is also generally accepted that prolonged exposure of the open wound is more likely to produce infective complications and thereby delay discharge of the patient from hospital.

Modification of the anaesthetic protocol ${ }^{6}$ to complement the advances in surgery has in turn allowed the rapid weaning of patients from ventilatory support and early extubation. The decision to extubate depends generally on the overall clinical picture and more specifically includes assessment of the conscious level of the patient and the ability to respond to commands, ability to breathe spontaneously and comfortably at a respiratory rate not exceeding 30 breaths a minute, and haemodynamic stability with acceptable blood loss.

Table 6 Reasons for admissions to intensive care unit after cardiac surgery

\begin{tabular}{lr}
\hline & No \\
\hline Preoperative clinical decision & 15 \\
Lack of space in cardiac surgical recovery area & 10 \\
$\begin{array}{l}\text { Transfers from cardiac surgical recovery area } \\
\text { after elective admission }\end{array}$ & 5.
\end{tabular}

*These patients were admitted to the intensive care unit after elective admission to the cardiac surgical recovery area, where elective admission to the cardiac surgical recovery area, where
their clinical status required them to have a prolonged ventilatory or cardiovascular support.
Measurement of blood gases allows supportive evidence of uncomplicated recovery. In only nine patients $(4 \%)$ did this policy prove inappropriate. It is possible that more detailed preoperative assessment of this group of patients would have led to their elective admission to the general intensive care unit.

Early extubation and rapid step down in dependency has both clinical and economic benefits. Early mobilisation, and return to normal nutrition have led to a shorter stay in hospital. Conventional intensive care had included elective postoperative ventilation for unnecessarily long periods. This, compounded by unnecessary sedation, led to delays in returning the patient to a normal ward and a protracted recovery. Reductions in the period of intubation, sedation, ventilation, and thus recovery time led to a rapid reduction in nursing dependency and hence nursing workload and supportive treatment. Most patients $(68 \cdot 1 \%)$ are discharged on the sixth postoperative day.

The final arbiter of this modified management of cardiac surgery patients must be patient morbidity and mortality. In this series a mortality of $0 \cdot 8 \%$ for 245 consecutive patients with a wide range and severity of cardiovascular problems supports the abandonment of the general intensive care unit for a more economical alternative; only a small group of patients "failed" this concept of postoperative cardiac care.

The recommended ratio of nurses to a bed in an intensive care unit is $7 \cdot 2$. The requirement in the cardiac recovery area is $3 \cdot 7$. The cost of an intensive care bed in this unit is $£ 750$ per day, whereas the recovery facility costs $£ 380$ a day. Also, short operating times allow for early extubation, so a particular bed is used twice in 24 hours.

These results support our initial contention that less than $7 \%$ of open heart patients require intensive care after surgery. The size and extent of an operation do not determine the need for intensive care, only conditions shown in a complicated medical history to require prolonged intensive care serve as criteria for admission to intensive care. Our experience has shown that admission of routine cardiac surgical patients to a general intensive unit is both unnecessary and a waste of resources.

1 Williams A. Economics of coronary artery bypass grafting $B M J$ 1985;291:326-9.

2 Tarhan S, White RD, Moffitt EA. Anaesthesia and postoperative care for cardiac operations. Ann Thorac Surg 1977;23:173-92.

3 Garfield BR, Myers JL, Kofke WA. Care of the cardiac surgical patient-the first 24 hours postoperatively. In Henley FA, Martin DE, eds. The practice of cardiac anaesthesia. Boston: Little and Brown, 1990

4 Varnauskas E, and the European Coronary Surgery Study Group. Twelve year follow up of survival in the randomized European coronary surgery study. $\mathrm{N} \mathrm{Engl} \mathrm{J} \mathrm{Med}$ 1988;319:332-7.

5 Mapleson WW. The elimination of rebreathing in various semi closed anaesthetic systems. Br J Anaesth 1954;26: 323-5.

6 Aps C, Hutter JA, Williams BT. Anaesthetic management and postoperative care of cardiac surgical patients in general recovery ward. Anaesthesia 1986;41:533-7. 